\title{
ESPELHO BARROCO: NAÇÃO E NARRATIVA EM SEMPREVIVA, DE ANTÔNIO CALLADO*
}

\author{
Marcus Vinicius de Freitas \\ Universidade Federal de Minas Gerais
}

Entre nosotros el barroco fue un arte de contraconquista.

Lezama Lima

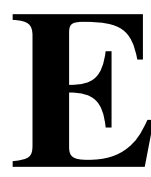

m entrevista a Zuenir Ventura, em 1993, incitado a falar sobre o Brasil enquanto projeto de nação, Antônio Callado revelava mais uma vez a sua perplexidade diante do país do futuro, cuja promessa parece fatalmente nunca se cumprir, e que tornava ainda mais amargo o autor de Sempreviva, já em luta contra o câncer que o levaria à morte:

O Brasil não ganhou guerra alguma! O Brasil ainda não fez coisa alguma! Não fez império, nada! O país não existe! Demarcou suas fronteiras esplendidamente, criou um palco magnífico, mas não fez peça alguma, não apresentou qualquer espetáculo. Lamento muito porque estou cercado de netos (...) Gostaria imensamente que eles crescessem num Brasil esplêndido, mas não teria coragem de mentir a eles, dizendo: "Podem ficar tranquilos porque, quando vocês tiverem a minha idade, vão ter a experiência de um país muito diferente do que eu tive." Não sei. Esta é uma pergunta que eu não sei responder. ${ }^{1}$

\footnotetext{
" Este trabalho foi originariamente apresentado à disciplina Nation and Narration, ministrada pelo Professor Doutor Luiz Fernando Valente, no Programa de Doutorado do Department of Portuguese and Brazilian Studies, Brown University, no Outono de 1996.
}

${ }^{1}$ VENTURA, 1993, p. 86. 
Se o escritor afirmava não ter uma resposta, reafirmava também a insistência da questão. A obra de Callado está marcada pela constatação da contradição entre um país pleno de possibilidades e parco de realizações; um país onde a miséria, moral e social, anda na inversa e exata proporção da riqueza material, espelhada no "palco magnífico", na exuberante natureza tropical. O conjunto da obra do romancista insistentemente tenta construir respostas para essa indagação, em um procedimento que enfatiza o caráter social da literatura e o compromisso histórico do escritor. Callado, sem dúvida, assinaria as seguintes palavras de Alejo Carpentier:

Y me pregunto ahora si la mano del escritor puede tener una misión más alta que la de definir, fijar, criticar, mostrar el mundo que le ha tocado en suerte vivir. Naturalmente, para ello hay que entender el lenguaje de ese mundo (...) Qué lenguaje es ese? El de la historia que se produce en torno a él, que se construye en torno a él, que se crea alrededor de sí, que se afirma en derredor suyo. No se trata evidentemente de tomar la prensa de todos los días y sacar de ella una conclusión literária, sino que se trata de ver, de percibir, lo que, en su propio medio, lo concierne a uno directamente, y de mantener la cabeza lo suficientemente fría como para poder escoger entre los diferentes compromissos que nos solicitan. ${ }^{2}$

Carpentier, ao mesmo tempo em que afirma a missão histórica do fazer literário, dá sua versão do que seja o romance histórico, o qual não se afirma por ser uma mera reprodução dos fatos, mas por ser uma tentativa de perceber aquilo que concerne aos indivíduos, aquele modo através do qual a história afeta diretamente cada vida em particular. Nesse sentido, os escritores seriam historiadores do quotidiano, daquilo que, estando à margem dos processos econômicos e políticos que parecem reger a história, e que por isso mesmo não vem descrito nas versões oficiais dos fatos, entretanto constitui os fragmentos onde mais luminosamente brilha a herança do passado, no que ela possa ter de trágico ou grandioso.

${ }^{2}$ CARPENTIER, Alejo, 1981, p. 45. 
Com certeza, essa parece ser a mesma postura de Antônio Callado. Para escrever essa outra história, faz-se necessário inventar uma outra linguagem, capaz de captar pelos desvãos os sentidos dispersos no tecido da história oficial. Não é gratuita, portanto, a aproximação que proponho entre Antônio Callado e Alejo Carpentier. Tratam-se de escritores de uma mesma geração e com uma mesma consciência histórica, fundamentada numa compre-ensão global dos problemas da América Latina, problemas esses derivados de um semelhante percurso colonial. Esta geração inclui, entre outros, Lezama Lima, Varga Llosa, Sarduy, Cortázar, Garcia Márquez, Rubem Fonseca, e mesmo os mais novos, e não menos importantes, João Ubaldo Ribeiro e Ricardo Piglia, entre tantos outros.

Pretendo então, neste trabalho, mostrar algumas das marcas dessa busca por uma linguagem ficcional capaz de dizer o interdito, presentes no romance Sempreviva. ${ }^{3}$

\section{A cobra tecedeira}

Sempreviva, no que concerne ao enredo, conta a história de Quinho, um ex-militante clandestino dos movimentos de esquerda dos anos 60, o qual, do exílio londrino, parte de volta ao Brasil, de maneira também clandestina, com vistas a encontrar e punir o torturador Claudomiro Marques, responsável pela morte de sua amada, Lucinda, raptada pela repressão diante de Quinho, durante uma sessão de cinema. No tempo presente do texto, Claudomiro Marques está travestido no onceiro Antero Varjão, dono da fazenda La Pantanera, em Corumbá, Mato Grosso do Sul, de onde trafica peles de animais e cocaína. Lá também, Claudomiro, um torturador afastado de seu ofício por falta de trabalho, relembra seus tempos áureos de ajuda aos organismos de repressão do Cone Sul, quando oferecia sua fazenda como local de tortura e morte de guerilheiros latino-ameri-

3 CALlADO, 1981. (Todas as refências à obra serão retiradas desta edição, com as páginas indicadas entre parênteses no próprio texto). 
canos. Torturados são também os animais caçados por Antero Varjão, em cenas que metaforizam os horrores dos porões do regime militar.

Como, segundo o texto, Quinho está fora do Brasil há dez anos, e levando-se em conta que ele e Lucinda parecem ligados aos movimentos guerilheiros que eclodiram com toda força por volta de 1968, parece que a ação se passa em torno de 1977/1978, quando a prática de tortura já havia regredido, como parte do regime de distensão do governo Geisel. Com certeza a ação se passa antes do processo da anistia, em 1979. As datas são aqui de somenos importância. Mais importante é a existência de um intervalo de tempo entre os eventos da tortura e a volta de Quinho, tempo esse que deixa sinais indeléveis na consciência de cada personagem. O texto de Callado interessa-se menos pelos eventos históricos, nesse caso a tortura, do que pelas marcas deixadas por aqueles eventos em cada ser humano, marcas essas que, visíveis nos indivíduos, quer através de suas cicatrizes, quer através de sua desestruturação mental, falam das outras profundas marcas deixadas no organismo social.

Entre Quinho e Antero Varjão circulam várias personagens: o espectro de Lucinda, às vezes corporificada na figura de Jupira Iriarte, a militante clandestina que ajuda Quinho em Corumbá; Herinha, filha de Jupira, que passa seu tempo entre conversas com a cobra Joselina e o sabiá Verdurino; e, sobretudo, o bird watcher Juvenal Palhano, máscara do legista-torturador Ari Knut, além de várias outras personagens secundárias.

Cada uma dessas personagens traz em si uma diferente marca da tortura. Sem constituir qualquer visão estereotipada do bem e do mal, o texto de Callado vê cada personagem como elo de uma cadeia histórica, personagens contaminadas, todas elas, por um mesmo veneno de miséria e destruição. Se, como diz Frederic Jameson, em relação ao romance latino-americano, "the story of the private individual destiny is always an allegory of the embattled situation of the public third-world culture and society" ${ }^{4}$, Callado nos

${ }^{4}$ JAMESON, 1986, p. 69. 
apresenta então uma alegoria verdadeiramente sombria da nação, pois fala de um mundo irremedia-velmente desestruturado pela violência. O embate entre a miséria cotidiana e o mundo melhor da utopia, sempre viva nas imagens da natureza redentora, constituem fundamento do romance Sempreviva, como de maneira geral de todos os romances do escritor.

Voltando ao tema principal, cabe perguntar: qual a linguagem capaz de falar ao mesmo tempo desse mundo desestruturado e da utopia, que se faz presente como desejo de transformação? Deixemos antes falar o próprio texto:

Herinha escorregou pelo tronco da palmeira carandá abaixo, e, à medida que conferia de novo os grãos de milho, de rua e roça, se encaminhava para o pai, o quintal, onde ia entregar à cascavel Joselina vários retalhos de histórias. Joselina era uma cobra costureira e sábia que enquanto chocalhava seus estojos de agulhas, as almofadas de alfinetes de cabecinha e os de fralda, as tesouras, os ovos de cerzir e os aros de bastidor, de pau, os dedais de prata e de ouro, aguardava que Herinha deixasse cair na cesta de costura os retalhos que tinha juntado de conversa de gente grande e - zás! - num segundo Joselina tinha entendido e armado o desenho que contava a história que, embora feita de remendos coloridos, diferentes entre si, era completa como uma roupa de arlequim ou uma colcha paraguaia. Pelos furos que Joselina fazia com a língua e deixava no retalho, Herinha enfiava o fio da linha. Um dia, pregados um no outro, os panos de Joselina iam contar a Herinha a história feita de todas as histórias, que davam a impressão de não ser a mesma coisa só por falta de agulha e de linha. (p. 147-148).

Tomando o ponto de vista da criança, que transparece no discurso indireto livre, o narrador tece o seu comentário metanarrativo: narrar é costurar retalhos, cerzi-los e bordá-los, para que o tecido resulte completo "como uma roupa de arlequim ou uma colcha paraguaia”. Ou seja, a colcha/narrativa resultante deixa entrever os fragmentos enquanto tais ver como tais, já que a visão da totalidade não passa de uma miragem. A História só pode ser vista como costura das múltiplas histórias, retalhos costurados pela agudeza dos variados pontos de vista - que são como agulhas sobre o tecido dos eventos - e pelas linhas de que se tece a narrativa. As 
"conversas de gente grande", imagem do discurso aparentemente estruturado da história oficial, são recosturadas pela mão da menina e pela língua da cascavel, portadora do pharmakon, remédioveneno que ao mesmo tempo pode matar e salvar. O pharmakon aqui, como no Fedro de Platão, serve de imagem à escrita, com seu poder de destruição e reconstrução da memória.

Para além do conteúdo da passagem, duas outras importantes questões sobre a narrativa aí se desvelam. Primeiramente, a escolha do ponto de vista narrativo. No trecho, como de resto em todo o romance, a linguagem narrativa aproxima-se da consciência das personagens e tenta apreender o mundo a partir do ponto de vista de cada uma delas. Se a história só pode ser vista através dos fragmentos, a narrativa espelha esta condição ao recusar o narrador onisciente, e constituir-se dialogicamente como embate de diferentes consciências.

Em segundo lugar, a reflexão metanarrativa aparece, não por acaso, através do ponto de vista de uma criança a brincar em seu quintal. A dimensão que o jogo infantil traz à reflexão revela-se de grande importância. Por ser infantil, o ponto de vista aqui é lúdico. A ludicidade narrativa constitui o mais fundamental elemento estruturante de um discurso ficcional que busca nomear o inominável, dizer o indizivel. Somente pelo jogo da linguagem pode-se ter acesso, através dos caminhos poéticos que aí se constroem, ao discursooutro, que nos liberta dos limites definidos da realidade para nos introduzir em outras dimensões, revelando assim o caráter ontológico dos procedimentos estéticos, como bem afirma Benedito Nunes:

É que o jogo estético, que suspende ou neutraliza, por meio da imaginação, a experiência imediata das coisas, dá acesso a novas possibilidades, a possíveis modos de ser que, jamais coincidindo com um aspecto determinado da realidade ou da existência humana, revelanos o mundo em sua complexidade e profundeza. Quando consumado através da linguagem, como criação literária, o jogo estético pode tornarse diálogo com o Ser. ${ }^{5}$

${ }^{5}$ NUNES, 1976, p.130. 
A observação de Nunes, construída originalmente a propósito da narrativa de Clarice Lispector, enfatiza o caráter mediador do jogo estético, capaz de transportar aquele que joga, seja o escritor ou o leitor, a diferentes apreensões do mundo que o cerca. O raciocínio do crítico se completa com a observação de que, numa obra literária, para que o jogo da linguagem alcance seu caráter revelador, faz-se necessário que a linguagem, além de ser o suporte material da ficção, "constitua também, de certo modo, o seu objeto". ${ }^{6}$

Outra não é a proposição do texto de Callado, que, dobrandose sobre o fazer da própria narrativa, coloca em evidência o caráter lúdico da linguagem ficcional e assume o jogo como possibilidade de conhecimento, funcional exatamente por assumir a condição fragmentária desse mesmo conhecimento:

Quem encontra as palavras exatas atinge a tranquilidade de espírito e só lhe faltavam umas poucas palavras - talvez uma só, uma única - para explicar Lucinda, e, explicada ela, reaver o sossego, a paz austera da acídia, feita, em partes iguais, na mesma ampulheta, de areia do deserto e pó da erosão de esfinges. Para explicar Lucinda, uma vez desenterradas, lavadas e filtradas as palavras que ainda não possuía, era só organizar o conhecimento que tivera dela - ah, ao conhecimento nunca chegara, aí é que estava o busilis: o conhecimento era o que buscava nas palavras, olha aí o círculo vicioso, pois ele só tinha de verdade a prática dos cinco sentidos, dos dez dedos e dos órgãos fálicos, isto é, o da fala e o outro. (p. 31)

A palavra exata, aquela capaz de trazer a paz do conhecimento, só se deixa revelar em momentos de jogo, em instantes epifânicos, nos quais brilham os fragmentos em ruína de uma história quase imemorial, os restos das esfinges erodidas, cujos cacos provêm do fundo dos tempos. Entretanto, esse conhecimento está limitado pelas contingências do tempo em que se vive e pelas fronteiras do corpo e dos sentidos. Assim sendo, não há conhecimento que possa ser totalizante, a não ser na epifania do instante.

${ }^{6}$ Idem, 1976, p.130. 
O percurso de Quinho é exatamente o de quem procura, através dos fragmentos do passado, experimentados como ruína no presente, construír para si mesmo uma história capaz de explicar seu próprio percurso, o qual the parece ininteligível. Trata-se de buscar a agulha e a linha capazes de dar sentido aos retalhos, num bordado que permita um novo uso do esfrangalhado tecido da história. O caminho de Quinho constitui uma história das perdas e a da luta pela reconstrução fragmentada de um horizonte possível.

A partir daquela colocação anterior de Frederic Jameson, poderíamos ler o percurso de Quinho como uma possível alegoria do caminho da nação, e também ler a fragmentação do discurso como o mecanismo capaz de contar as histórias que não puderam ser contadas pelos fatos em si mesmos. Há aí, explicitamente, uma consciência nietzscheana de que a história deve servir ao presente, uma outra marca da ficção de Callado.

A linguagem narrativa de Sempreviva, portanto, nunca se apresenta como linear. Ao contrário, faz-se de fragmentos, espelhase no jogo das diferentes consciências e na proliferação das incursões metanarrativas. Através do estatuto homodiegético do narrador, do embate das vozes, dos diversos pontos de vista adotados durante a narrativa, os quais se apresentam pelo discurso indireto livre, que deixa fluir o contraditório pensamento de cada personagem, através de todos esses recursos, a narrativa de Antônio Callado passa uma visão nada tradicional do que seja um romance histórico, porque a própria história não é vista aqui como um contínuo de fatos, mas como um processo de marchas e contramarchas, como uma rede onde os vazios são tão significativos quanto as linhas de que ela se tece.

\section{O espelho barroco}

Falei até agora de dois elementos em especial, quais sejam: de um profundo sentido histórico da obra de Antônio Callado, autor que só compreende o Brasil no contexto da América Latina; e da 
consciência autoral sobre o jogo da linguagem, tomado como processo construtivo capaz de informar aquele olhar sobre a história. Associando esses dois elementos, somos levados, por três motivos simultaneamente, a pensar nos procedimentos barrocos do autor. Em primeiro lugar, pela larga associação, feita por inúmeros teóricos, entre o jogo da linguagem e a estética barroca; ${ }^{7}$ em segundo lugar, pela assunção, feita por diversos pensadores, do barroco como sendo um elemento histórico definidor da América. Entre esses escritores, destacam-se Alejo Carpentier, Lezama Lima e Severo Sarduy, todos integrantes da mesma geração e possuidores da mesma consciência histórica de Antônio Callado; em terceiro lugar, porque o próprio texto de Sempreviva remete constantemente ao barroco como elemento construtivo.

Afonso Ávila associa o jogo com a estética barroca, como uma maneira de demonstrar a consciência do sujeito sobre o mundo:

o artista barroco não se aliena ao jogar, porquanto o jogo se torna seu instrumento de rebeldia, de libertação, de afirmação perante a realidade que quer sufocá-lo e anular, pela pressão histórica, a sua plenitude de ser no mundo. ${ }^{8}$

O jogo barroco aparece então como forma de dominar a história. A obliqüidade barroca seria o que permitiria, pelos desvãos, o aparecimento de uma consciência diferenciada sobre o mundo. Assumindo a existência como jogo (la vida es sueño, diria Segismundo), o homem barroco suspende os critérios de valoração da verdade e faz brilhar o caráter discursivo da história.

Quando Quinho se dirige pela primeira vez a La Pantanera, a fazenda de Antero Varjão que serviu como teatro de horrores para a morte de Corina e Violeta - as duas militantes argentinas, seviciadas e enterradas na antiga senzala -, o narrador faz uma comparação

\footnotetext{
${ }^{7}$ Ver, entre outros, HOCKE, 1978; HAUSER, 1982; HUIZINGA, 1982; ÁVILA, 1980; SARDUY, 1982.

8 ÁVILA, 1980, p.35.
} 
muito reveladora: "Como o céu por trás da casa anunciasse tormenta, lívido e esverdeado, La Pantanera fez Quinho pensar em Gôngora, em Greco e em Toledo" (p. 34). A poesia, a pintura e a arquitetura barrocas espelhando a imagem de La Pantanera, palco das mais terríveis violências contra os animais, num processo de inversão entre o que se pressupõe e o que se revela como verdadeiramente selvagem:

Mas por que assim pendurados, os bichos mortos, pregados em árvores, estirados em varais, antes mesmo de terminada a esfola, como aquela onça preta, suspensa dum galho de árvore por dois ganchos que lhe arregaçavam os beiços, como se a pobre suçuarana tivesse literalmente morrido de rir? (p. 41)

Os suplícios dos animais rondam toda a narrativa como um espectro da tortura de homens. A natureza do Pantanal comporta ao mesmo tempo os torneios da poesia de Góngora, as volutas da arquitetura de Toledo e as figuras longilíneas de El Greco, todas imagens disformes dos supliciados. Na terribilitá barroca do texto de Callado, La Pantanera constitui, por um lado, a exuberância da natureza tropical, com os pelos de ouro e sombra das onças, que fazem pensar nos torneios da arquitetura e nos adornos de ouro das igrejas, e revela, por outro, o inferno terrífico ao qual Quinho se dirige, como um Orfeu, em busca do espectro de Lucinda. O mesmo paradoxo do terrível e do sublime faz Juvenal Palhano deliciar-se tanto com o canto mavioso de Verdurino como com a perversão das plantas carnívoras. Cada imagem sublime esconde sob sua máscara uma face terrível: o bom Juvenal é também o frio legista Ari Knut, que controlava cientificamente o processo de tortura infligido por Antero Varjão/Claudemiro Marques, outro ser de dupla face. Duplo revelase também Quinho, o qual, lutando contra o fantasma da tortura, inflige a Claudemiro a mesma morte terrível que este infligia aos animais, aspergindo sobre o onceiro bêbado o sangue das onças recémabatidas e soltando sobre ele os cães famintos. Dupla também é Herinha, que carrega em sua chapeleira tanto o sabiá Verdurino quanto a cobra Joselina, como numa caixa de Pandora de onde pode sair tanto o remédio consolador do canto, como o veneno da cascavel. 
Desta forma, não há personagens puros, como pura não é a história em que se inserem. A verdade histórica aí aparece como um ponto de vista construído, e por isso mesmo ambíguo. Sigamos a afirmação de Severo Sarduy:

El espectáculo del barroco (...) difiere al máximo la comunicación del sentido gracias a un dispositivo contradictorio de la mis-en-scéne, a una multiplicidad de lecturas que revela finalmente, más que un contenido fijo y unívoco, el espejo de una ambiguedad.?

A ambigüidade constitui a figura fundamental usada por Callado no processo de construção das personagens, os quais funcionam como espelhos em que se revelam a imagem das ambiguidades históricas da própria nação. Se, como aponta Benedict Anderson, as nações são comunidades imaginadas, e que devem ser distintas não pelo que nelas há de verdade ou falsidade, mas pelo estilo através do qual cada uma delas é imaginada, ${ }^{10}$ poderíamos dizer que o estilo com que Callado imagina sua nação é o barroco, pelo que há nesse estilo de ambíguo, de alegórico e mesmo de fragmentário, uma vez que a cosmovisão barroca não permite totalizações lineares. Sobre o caráter alegórico dos procedimemtos narrativos do romance, vale lembrar que a morte das prisioneiras políticas na senzala da fazenda constrói, por sua vez, uma outra alegoria que ultrapassa as fronteiras do romance, e que aponta para a própria história da nação brasileira, com seu percurso de violência e impunidade.

A assunção do barroco enquanto elemento construtivo, prática que estou tentando mostrar em Antônio Callado, se faz explícita no discurso de dois outros escritores latino-americanos, que vão claramente relacionar barroco e americanidade: Alejo Carpentier e Lezama Lima. Se este último afirma que "entre nosotros el barroco fue un arte de contraconquista," 11 apontando o caráter de resistência

\footnotetext{
${ }^{9}$ SARDUY, 1982, p.78.

${ }^{10}$ ANDERSON, 1983.

${ }^{11}$ LEZAMA LIMA, 1969, p.34.
} 
da arte barroca em relação ao processo colonial - em afirmação semelhante à de Afonso Ávila - Carpentier, por seu lado, vai mais longe ainda e afirma:

Y por qué es America Latina la tierra de elección del barroco? Porque toda simbiosis, todo mestizaje, engendra un barroquismo. El barroquismo americano se acresce con la criollidad, con el sentido del criollo, con la consciencia que cobre el hombre americano (...) de ser otra cosa, de ser una cosa nueva. ${ }^{12}$

O barroco, visto desta forma, seria capaz de engendrar novas visões do mundo exatamente por seu caráter de simbiose e por sua perspectiva diagonal, que deixariam abertas fendas por onde se pudesse apôr um novo olhar sobre a realidade. Sobretudo a natureza americana, com sua pujança informe, seria a imagem que concretizaria esse discurso de possibilidades. Tomemos um exemplo vindo de Antonio Callado.

Uma das mais fortes imagens do romance Sempreviva está contida na figura do sabiá Verdurino, ícone da pátria perdida, assim retomado pelo próprio Quinho através do poema de Gonçalves Dias: "mas Quinho só tinha olbos para Verdurino, o sabiálaranjeira, sabiá como só trina e canta na palmeira das saudades do exilado, do asilado, do banido" (p. 28). O mesmo sabiá brilha nos olhos de Cravina, a negrinha arisca, empregada da casa de Juvenal Palhano (p. 82). A mesma imagem está também associada aos "seios mulatos de Jupira, mas com os bicos de um castanho róseo, muito sabiá-laranjeira" (p. 64). O sabiá representa ao mesmo tempo terramãe e o corpo de Lucinda, que o exilado Quinho aspira como utopia de repouso e apaziguamento. Mas o sabiá, sobretudo, concretiza a imagem de uma história não-acabada, de uma possibilidade de improvisos sobre pauta em aberto. Juvenal diz a Quinho que, graças a um sabiá daquela região (que o texto deixa transparecer como sendo o próprio Verdurino), as pesquisas do musicólogo Wolfgang Schwartz tomaram uma nova e inesperada direção:

12 CARPENTIER, 1981, p.126. 
Os pássaros antigamente improvisavam, não tinham canto fixo, uma estria só, uma única trilha nas cordas vocais, fato que uma vez documentado, estabelecido, nos dará condições de agir, para subirmos de volta a corrente, por assim dizer, e restaurar a livre invenção melódica da natureza, percebeu, amigo Quinho, ouviu a música desta pesquisa, da Nona Sinfonia, a Coral, e da Nona Elegia, a de Duino? (p.124).

Subindo de volta a corrente da história, poder-se-ia reencontrar um tempo em que essa mesma história estava em formação, com sua pauta aberta aos mais diversos improvisos, às mais diversas leituras. Callado constrói aí a imagem da possibilidade utópica de reconstruir o destino, reaprendendo o caminho dessa reconstrução através da natureza plena de possibilidades, ou através de um discurso que não se apresente fechado, de um discurso que recuse a verdade única da história e faça com que ela se abra ao improviso, ao contraditório e ao ambíguo.

Vejamos apenas mais um exemplo da reflexão metanarrativa que se vale do barroco como imagem construtiva. No diálogo que se segue ao primeiro encontro amoroso entre Jupira e Quinho, diz este último:

Eu frequentemente examino pessoas e encontros pelo lado parvo e graúdo do binóculo, que faz muito nítidas mas muito distantes as coisas as mais próximas, o que as torna meio doidas, não é mesmo, feito os pintores holandeses pondo a refletir num espelho ao fundo a cena banal do primeiro plano, que fica dúbia e inquietante... (p. 66).

O recurso ao espelho de fundo é comum não apenas aos pintores flamengos, mas também ao realismo barroco espanhol (lembremo-nos das Meninas, de Velásquez). Nesses pintores barrocos, o recurso ao espelho de fundo serve como contraponto à cena de primeiro plano, que ganha uma inquietação nova através do espelho que a deturpa e a revela de maneira diferente. O espelho, para os maneiristas e barrocos, constitui propriamente um concetto, sendo ao mesmo tempo recurso e comentário narrativo. Parece-me ser exatamente esse procedimento de Antônio Callado, que põe a cena "banal" da versão oficial da história em contraste com esta cena outra, deformada pelo espelho da narrativa, pela multiplicidade de 
imagens que sobre esse espelho se projetam, criando desvãos nos quais brilham outras formas de ver a mesma cena.

\section{O jogo dos contrários}

Os Iriarte, Jupira e seu pai, bem como a própria Herinha, são criadores de cobras, das quais extraem e vendem o veneno, em troca de soro anti-ofídico. O veneno de cobra, que produz seu próprio soro, concretiza a máxima da medicina homeopática de Hanemam, similia similibus curantur, máxima detestada pelo velho Iriarte, que a ela contrapõe, um tanto parodisticamente, um outro bordão: contraria contrariis curantur. Como os Iriarte são de uma família de comunistas, com velhas raizes anarquistas, o bordão adquire na narrativa um caráter de ação política, que pode ser estendida a uma possível consciência do autor sobre o papel social da literatura.

Neste mundo de Sempreviva, em que todas as personagens estão contaminadas, envenenadas por uma história de misérias, parece ser preciso usar o veneno, em sua condição de pharmakon, para curar as feridas abertas pela violência, como aberta parece estar a cicatriz na mão de Quinho. A chaga, que toca na palma da mão a linha de sua vida, toca também a história da nação-utopia que Quinho sonha poder reencontrar, reencontrando Lucinda, a sempre viva, imagem desta mesma nação utópica.

Entretanto, o veneno não é visto como o igual que cura o igual, mas como o contrário a curar o contrário. A inversão do bordão aponta para uma atitude amarga e de combate, que não permite ingênuos apaziguamentos. Não por acaso, após a morte de Claudomiro Marques e Juvenal Palhano, o autor mata também a figura de Quinho, como a recusar qualquer procedimento catártico por parte da literatura. Não a catarse, mas sim a consciência histórica.

O romance Sempreviva não aponta respostas, como antes apontava Quarup, onde o engajamento da personagem Nando no processo da guerrilha urbana cumpria o papel de uma pedagogia social. Diferente era o Brasil quando Callado escreveu Quarup, o 
que, comparando-se com Sempreviva, revela uma mudança nas concepções tanto narrativas quanto históricas do escritor. A imagem final de Sempreviva, com a morte tão tola de Quinho, não quis apontar caminhos, mas apenas reforçar a perplexidade do autor diante do mundo que o cercava. Perspectiva aparentemente mais sombria, mas sobretudo de uma profunda dignidade intelectual. Pois mesmo parecendo sombria, a imagem final deixa brilhando na mente do leitor o reencontro, ainda que mágico, ou mesmo transcendente, de Quinho com sua amada Lucinda "perene, perpétua, imortal, sempreviva.” (p. 289). Se não há o otimismo militante de Quarup, existe aqui a crença de fundo numa possibilidade de transmutar o destino da nação, pela leitura consciente que se possa fazer dos desvãos de sua história.

\section{Referências Bibliográficas}

ANDERSON, Benedict. Imagined Communities. London - New York: Verso, 1983.

ÁVILA, Afonso. O lúdico e as projeções do mundo barroco. São Paulo: Perspectiva: 1980.

CALlADO, Antônio. Sempreviva. 5. ed. Rio de Janeiro: Nova Fronteira, 1981.

- Quarup. 7. ed. Rio de Janeiro: Civilização Brasileira, 1974.

CARPENTIER, Alejo. Papel social del novelista. In: La novela latinoamericana en vísperas de un nuevo siglo - y otros ensayos. Madrid: Siglo Veintiuno, 1981.

HAUSER, Arnold. Maneirismo. São Paulo: Perspectiva, 1982.

HOCKE, Gustav René. Maneirismo: o mundo como labirinto. São Paulo: Perspectiva, 1978.

HUIZINGA, Johan. Homo ludens. São Paulo: Perspectiva, 1982.

JAMESON, Frederic. Third-world literature in the era of multinational capitalism. In: Social Text. 15, Fall 1986. 
LEZAMA LIMA, Jose. La expressión americana. Santiago de Chile: Universitaria, 1969.

NUNES, Benedito. O dorso do Tigre. 2. ed. São Paulo: Perspectiva, 1976.

SARDUY, Severo. La Simulación. Caracas: Monte Avila, 1982.

VENTURA, Zuenir. 3 Antônios e 1 Jobim. Rio de Janeiro: RelumeDumará, 1993.

\section{Resumo}

Este trabalho se propõe a analisar o romance Sempreviva, da autoria de Antônio Callado, a partir dos procedimentos de extração barroca característicos de sua narrativa. O barroco, tal como caracterizado por Sarduy, Lezama Lima e Carpentier, e tal como utilizado por Callado enquanto metáfora construtiva de seu romance, deixa entrever a possibilidade de uma leitura da história nacional a partir de seus vazios. As relações entre história e literatura revelam-se então a partir de uma compreensão da ficção como uma possível estratégia de leitura da história.

\section{Abstract}

This works aims at analysing Antônio Callado's Sempreviva, from the viewpoint of the baroque elements which characterize its narrative. The baroque style, defined by Sarduy, Lezama Lima and Carpentier, among others, as well as used by Callado in the process of constructing his novel, helps the novelist in his task of constructing a new approach to the matters of national identity and natinal history. Yet, the relationship between history and literature reveals itself as a strategy for reading the oficial history. 